\title{
Consumo audiovisual em plataformas digitais: a configuração de práticas e fluxos na rotina de usuários da Netflix
}

\author{
Vanessa Amália Dalpizol Valiati' \\ https://orcid.org/0000-0001-9183-2301 \\ I - Universidade Feevale \\ Nova Hamburgo (RS), Brasil.
}

Resumo: O artigo aborda as práticas relacionadas ao consumo de conteúdo audiovisual em plataformas digitais a partir do estudo da relação dos usuários com a Netflix, sob o viés da teoria da prática. A reflexão parte do resultado da tese de doutoramento da autora, que envolveu a coleta de dados quantitativos e qualitativos. Neste artigo, são discutidos os resultados das entrevistas e a observação dos espaços de consumo dos usuários. Em termos gerais, nota-se o estabelecimento e a reprodução de fluxos de consumo interconectados, nos quais usuários e empresa relacionamse recursivamente: de um lado, há a disponibilização contínua de conteúdo, e do outro, o acesso rotinizado, fragmentado e marcado pela insaciabilidade e autonomia do tempo dedicado à prática, o que favorece a manutenção da estrutura estabelecida pela plataforma.

Palavras-chave: consumo audiovisual; plataformas digitais; Netflix.

Abstract: Audiovisual consumption on digital platforms: configuring practices and flows in the routine of Netflix users - The paper addresses the practices related to the audiovisual consumption on digital platforms based on the study of users' relationship with Netflix, under the practice theory approach. This reflection starts from the result of the author's doctoral thesis, which involved the collection of quantitative and qualitative data. In this article, the results of the interviews and the observation of users' consumption spaces are discussed. In general terms, there is the establishment and reproduction of interconnected consumption streams, in which users and companies recursively relate: on the one hand, there is continuous availability of content, and on the other, routinized access, fragmented and marked by insatiability and autonomy of the time devoted to the practice, which favors the maintenance of the structure established by the platform.

Keywords: audiovisual consumption; digital platforms; Netflix. 
A compreensão do cenário do consumo midiático contemporâneo inclui a percepção de modificações significativas nas práticas cotidianas e experiências relacionadas a produtos audiovisuais. Essas alterações são perceptíveis ao analisarmos o uso rotineiro dos artefatos de mídia. Com acesso ao conteúdo sob demanda via streaming se tornando cada vez mais popular, os usuários vêm se familiarizando com novas práticas ou remodelando comportamentos de consumo já incorporados.

Ao longo do tempo, a Netflix, empresa fundada em 1997, na Califórnia (EUA), e um dos principais serviços de streaming por assinatura em funcionamento no Brasil, vem ganhando centralidade no que diz respeito às práticas relacionadas ao consumo de conteúdo audiovisual sob demanda. Com mais de 167 milhões de assinantes em mais de 190 países, a empresa passou rapidamente de distribuidora à produtora de conteúdo original, e de parceira à concorrente dos grandes estúdios. A empresa estabelece um padrão de consumo específico com novas rotinas e procedimentos para o consumo de conteúdo audiovisual, como por exemplo, a popularização de práticas como o bingewatching, modo de consumo no qual a audiência assiste a diversos episódios de produtos audiovisuais - na sequência temporal em que desejam, sem a necessidade de pausas semanais ou intervalos comerciais (JENNER, 2014, 2015; MCCORMICK, 2016; PERKS, 2015, SACCOMORI, 2016).

Para compreender esse cenário, parte-se da abordagem da teoria da prática, originária da antropologia e sociologia que, embora não seja sistematicamente elaborada como um campo de estudos (POSTILL, 2010; RECKWITZ, 2002), tem a prática como um ponto de partida em vez de estruturas, sistemas, indivíduos ou interações (POSTILL, 2010). A prática, portanto, é considerada como um comportamento rotinizado, com vários elementos interconectados em uma relação constante entre agentes e objetos (RECKWITZ, 2002). Assim, este estudo tem como objetivo investigar como as múltiplas camadas que constituem as práticas estruturadas em torno do consumo de conteúdo audiovisual na Netflix estão articuladas às rotinas de usuários da plataforma.

\section{Consumo, prática e eixos de investigação}

O campo do audiovisual contemporâneo é formado pelas mais diversas interfaces, vídeos, usos e ambientes (MONTAÑO, 2015). Sob esse aspecto, a conveniência proporcionada pelo avanço tecnológico alia-se a um espectador ativo e cada vez mais insaciável. Sobre a insaciabilidade, Barbosa (2004, p.49) resume: "Não é a simples permanência de um sentimento de insatisfação, de um eterno 'querer mais', mas a existência de uma insaciabilidade para com novos produtos".

A insaciabilidade do novo consumidor, aliada à satisfação de desejos e vontades, pode ser identificada nos processos de consumo audiovisual. A ideia de assistir a "só mais um episódio" de um seriado e a relação de negociação e deslocamento do tempo dedicado 
a outras práticas - antes direcionado a atividades básicas como o sono ou alimentação (PERKS, 2015) - podem ilustrar os aspectos característicos das práticas relacionadas a esse processo.

Douglas e Isherwood (2013, p.110) definem o consumo como um processo ritual que dá sentido ao fluxo dos acontecimentos. Segundo os autores, "rituais são convenções que constituem definições públicas visíveis" e servem para conter as flutuações de significados. Segundo Martín-Barbero (2015, p.19), os rituais, em sua relação com os formatos industriais, constituem as "gramáticas da ação, que regulam a interação entre os espaços e tempos da vida cotidiana e os espaços e tempos que conformam os meios". E, com relação ao consumo, as ritualidades dizem respeito aos diferentes usos sociais dos meios e às múltiplas trajetórias de leitura (que estão ligadas aos saberes constituídos, hábitos familiares, às condições sociais do gosto, entre outros). Esse ritual está presente nas relações estabelecidas pelos usuários com a Netflix, as quais serão exploradas neste texto.

Dessa forma, a teoria da prática oferece aos estudos da mídia novas formas de tratamento para questões centrais ao campo da comunicação (POSTILL, 2010). Couldry (2010, p. 36) ${ }^{1}$, propõe um novo paradigma para os estudos de mídia, que pode ser resumido como o estudo do "conjunto aberto de práticas relacionadas ou orientadas em torno da mídia", compreendendo os entrelaçamentos entre a mídia e as relações de poder que se embaralham com a vida cotidiana. Assim, para o autor, o olhar do pesquisador deve dirigir-se às dinâmicas mais abrangentes que moldam o cenário da produção e consumo midiáticos. É importante destacar que o autor propõe pesquisar a mídia a partir não apenas dos textos ou instituições, como acontece nas pesquisas limitadas à audiência, mas também da prática voltada para entender o que as pessoas estão fazendo em relação à mídia em uma gama de situações e contextos diferentes.

Logo, a base para a sistematização dos dados desta pesquisa parte do trabalho de Shove, Pantzar e Watson (2012), que, seguindo a perspectiva de Schatzki $(2001,1996)$ e Reckwitz (2002), reconhecem que a prática é definida pelas relações interdependentes entre materiais (objetos, tecnologias, entidades fisicamente tangíveis, e matérias das quais os objetos são feitos), competências (habilidades, know-how e técnicas) e significados (que inclui sentidos simbólicos, ideias e aspirações). Segundo os autores, as ligações entre os elementos têm de ser renovadas constantemente e, além disso, a estabilidade e a rotina não são pontos finais do processo. Em vez disso, elas devem ser entendidas como realizações contínuas em que elementos semelhantes são repetidamente ligados.

Sob esse aspecto, portanto, este artigo é parte de uma pesquisa mais ampla² composta de uma primeira fase quantitativa, seguida pela coleta de dados qualitativos. Esta discussão apresenta dados coletados a partir da entrevista e observação realizadas com 12 indivíduos com faixa etária entre 18 e 40 anos, moradores da região sul do Brasil (Porto Alegre e

1 Do original: "the open set of practices relating to, or oriented around, media". Tradução nossa.

2 A pesquisa completa, com a consolidação dos dados quantitativos pode ser encontrada nos resultados da tese de doutorado da autora (VALIATI, 2018). 
região metropolitana) ${ }^{3}$, que relataram o uso da Netflix como intenso ou moderado (mais de 4 horas semanais), selecionados na fase quantitativa da pesquisa, por meio de um questionário prévio divulgado em plataformas de redes sociais ${ }^{4}$. Esses respondentes foram escolhidos a partir de um sorteio simples, tendo como base o percentual de ocorrência de respostas em cada faixa etária. Foram nove entrevistados com percepção de uso intenso e três de uso moderado. Sete entrevistados são da capital, Porto Alegre, e cinco da região metropolitana ${ }^{5}$. Há também uma predominância do gênero feminino (10 mulheres e 2 homens) - essa proporção é resultado das respostas obtidas na fase quantitativa ${ }^{6}$.

Os usuários foram observados em sua relação com a plataforma e o ambiente de acesso e relataram a sua rotina de utilização da Netflix. Os elementos do esquema de Shove, Pantzar e Watson (2012) foram utilizados como alicerce para agrupar e organizar a multiplicidade de aspectos observados, reiterando que eles estão em constante interconexão e que a prática em si não existiria com esses mesmos elementos isolados. Assim, as interações do usuário com a plataforma foram analisadas ao longo dos cinco eixos: a) aspectos materiais: os objetos, as questões relacionadas à plataforma, as affordances ${ }^{7}$ do sistema, a multiplicidade de telas, os algoritmos e sistema de recomendação, as restrições e possibilidades; b) competências: estão ligadas às habilidades necessárias para o acesso e navegação na plataforma e reconfiguração de capacidades cognitivas e de sensorialidades, como a atenção e capacidade de assistir ao conteúdo em múltiplas telas, por exemplo; c) dinâmicas afetivas: engajamento com a plataforma e o papel atribuído a ela no consumo midiático dos respondentes - ligado aos significados, esse eixo investiga as percepções afetivas na esfera individual; d) dinâmicas relacionais: os processos de socialização viabilizados a partir da prática, entrelaçado também às questões afetivas, esse eixo trata das relações em uma esfera coletiva; e) dinâmicas espaço-temporais: os aspectos relacionados à organização das dinâmicas espaço-temporais na vida cotidiana em torno da plataforma.

Cabe ressaltar que, embora o ponto de partida da teoria da prática não seja a interação, torna-se impossível descolar o indivíduo do cenário social em que se encontra e das relações que estabelece; portanto, neste estudo detecta-se a necessidade de enfatizar esse aspecto, ainda que, nos modelos de pesquisas anteriormente mencionadas (SHOVE; PANTZAR; WATSON, 2012), as relações sociais/interação e as dinâmicas espaço-temporais não apresentem uma posição de destaque.

3 O critério geográfico foi estabelecido em função da necessidade de encontros presenciais para a entrevista e observação.

4 O questionário foi disponibilizado pelo Facebook e enviado via e-mail. Criado a partir da ferramenta Formulários Google, ficou disponível no período compreendido entre 04 e 11 de outubro de 2017 e obteve 860 respostas. A intenção inicial era a obtenção de um filtro para a seleção da amostra, mas como o número de respostas foi significativo, os dados puderam ser utilizados em conjunto com a pesquisa qualitativa.

5 Residentes nos municípios de Novo Hamburgo, Taquara e Parobé.

6 Em relação às respostas do formulário, 71,6\% dos respondentes declaram-se do gênero feminino, e 27,6\%, masculino.

7 O conceito, idealizado por Gibson (1977), consiste originalmente na relação entre as propriedades do ambiente e o comportamento de animais. Nesse caso, pode-se compreender as affordances como as possibilidades oferecidas pelo sistema. A ideia foi adaptada aos diversos campos do conhecimento, como foco nas relações entre humanos e objetos, tais como design, tecnologia e comunicação 


\section{"[...] A Netflix é a minha rotina": breve apresentação dos resultados}

Com relação aos aspectos materiais é possível perceber que o suporte preferencial para o consumo digital de produtos audiovisuais via streaming da maioria dos entrevistados é a televisão. Dentre os motivos para a escolha do suporte citados estão: as dimensões da tela, o conforto e a ideia de maior atenção atrelados à ideia do uso da televisão em detrimento a outros artefatos. É possível inferir também que a escolha do conteúdo se transformou em uma atividade complementar à visualização. Ou seja, o processo de escolha é parte integrante do ritual de consumo, que por vezes satisfaz só pelo fato de selecionar o que assistir.

Foi possível apreender, a partir das entrevistas, as noções dos usuários relacionadas aos algoritmos e aos sistemas de recomendação e classificação do conteúdo. De maneira geral, esse aspecto é tido como uma relação mútua e benéfica: os respondentes gostam de classificar o conteúdo, pois isso auxiliaria o sistema a lhes enviar as recomendações mais adequadas a seu gosto, enquanto a empresa se beneficia com as informações sobre os hábitos de visualização. Esse mapeamento de gostos e perfil de consumo parece não desagradar aos usuários da Netflix entrevistados para esta pesquisa. Como ilustra a Respondente 12: "Meu problema é muita opção e dificuldade para escolher. Então, para mim é uma vantagem que seja moldado no meu perfil [...]".

Com relação às competências, os entrevistados demonstraram conhecimento adequado ao desempenho da prática, ou seja, apresentaram familiaridade com o gerenciamento de senhas e perfis, os limites do plano escolhido e telas de acesso, bem como sobre os gêneros e sistemas de busca. Ao analisar as telas de entrada na plataforma, foi possível perceber que as contas apresentam um senso de coletividade: ou seja, a criação de um perfil na conta de um familiar, e, no caso dos assinantes, a criação de perfis para os familiares/amigos na sua assinatura e compartilhamento de senhas. Com a proliferação do número de telas no cotidiano, grande parte dos entrevistados relaciona o foco e a capacidade de executar outras tarefas enquanto assiste à Netflix, além das affordances do suporte, ao tipo de conteúdo assistido. Ou seja, a complexidade da narrativa tem influência sobre as práticas envolvidas na visualização. Para a Respondente 12, a atenção e a capacidade de fazer outras coisas ao mesmo tempo também depende do conteúdo. "Se é uma série que exige mais atenção, eu fico com a atenção ali. Agora, se é uma série mais de comédia, consigo captar só pelo áudio, [...] eu fico no Whatsapp, no Facebook e vou ouvindo".

No que tange às dinâmicas afetivas e relacionais é possível perceber que, dentre a amostra desta pesquisa, a Netflix adquiriu um espaço de destaque na rotina dos indivíduos. A Respondente 12 compreende a plataforma como uma válvula de escape, da hora em que chega do trabalho até a hora de dormir. "Eu acho que é uma fuga da realidade. É uma experiência que eu tenho num universo de ficção que eu consigo fugir do dia-a-dia". Ainda nesses eixos de investigação, as reações ao fim de uma temporada ou série, após 
a realização das maratonas, é outro aspecto a ser destacado. Grande parte dos entrevistados recorreram à expressão "sensação de vazio" para descrever o sentimento predominante. Sono, angústia e dever cumprido também figuraram entre as respostas. O Respondente 2 compara o final de uma maratona à sensação de ressaca, tal qual o significado do termo binge $(\text { farra })^{8}$. "Eu fico deprimido [...]. Sabe bebida alcóolica? Sabe quando tu sai para tomar um drink com o pessoal [...]. É a mesma sensação. A ressaca no dia posterior [...]".

O cansaço, em função do tempo dedicado à prática, também foi mencionado, mas de acordo com a Respondente 5, compensa. "É um cansaço que vale a pena". A Respondente 6 também se refere a "uma sensação boa", de dever cumprido. "Porque, tu viu toda a temporada [...] tu venceu aquela temporada. Então, quando eu termino, eu tenho uma sensação melhor, não termina no meio do caminho". Já a Respondente 9 refere-se a um "vazio bom", porém faz uma ressalva: "Mas quando é aquela série que acabou, que é a última temporada, eu paro e fico olhando para o nada por muito tempo. Dá um vazio muito grande". É importante ressaltar que, pelo teor das conversas, essa sensação perdura até o engajamento com uma nova série.

Os sentimentos de amor, culpa, traição, depressão e vazio mencionados pelos entrevistados denotam a dimensão afetiva dos significados que a Netflix adquire entre as atividades rotineiras dos usuários. Isso permite inferir que a plataforma adquire significados que vão além da descrição usual de produtores e distribuidores de conteúdo de streaming e são capazes de produzir fortes ligações com os consumidores, como ilustrado pela Respondente 5: "a Netflix é o amor da minha vida". Esses laços baseados em emoção compõem, reforçam e mantêm o desempenho da prática.

No aspecto relacional, a plataforma está presente na relação dos entrevistados com amigos e conhecidos, em conversas presenciais ou plataformas de redes sociais ou grupos em serviços de mensagens eletrônicas, na maior parte das vezes, após as sessões de visualização. O conteúdo assistido, segundo a maior parte dos entrevistados, fornece o assunto para a interação - em especial para os momentos de conversa de bebedouro ${ }^{9}$ assim como ocorria (e ainda ocorre) com o fluxo televisivo (como por exemplo, novelas, reality shows e acontecimentos vistos na televisão são comentados e geram repercussão). É possível perceber, portanto, o gerenciamento relacionado ao conteúdo e à companhia. "É bem dividido. Eu acho que eu assisto mais acompanhada do que sozinha[...] (Respondente 10)". O consumo do conteúdo na Netflix, principalmente as séries, na concepção da maior parte dos entrevistados também é capaz de gerar a sensação de pertencimento ou exclusão em um grupo e também pautar a conversação.

8 Embora não haja uma tradução específica para a língua portuguesa, é possível compreender a expressão como: "[...] uma espécie de orgia televisiva: binge significa 'farra', um comportamento de excessos em um curto período de tempo, enquanto watching significa 'assistindo'. Assim, teríamos o significado próximo de assistir compulsivamente. A mesma composição é utilizada, em outros campos, ao descrever comportamentos como binge-eating ou binge-drinking, comer ou beber em excesso". (SACCOMORI, 2016, p. 26).

9 "Water cooler talk": expressão que remete a conversas casuais, em ambiente comuns, sobre temas exibidos pelas mídias, como o último capítulo da novela ou alguma notícia do telejornal. 
Nesse sentido, as práticas são comportamentos que aparecem em diferentes locais e pontos de tempo (RECKWITZ, 2002). Por isso torna-se necessário tratar desses aspectos e suas dinâmicas relacionadas ao consumo de audiovisual sob demanda. A rotina é considerada aqui a ferramenta que organiza o fluxo do tempo, e, dessa forma, cria ritmos e padrões temporais (GIDDENS, 2009; EHN, LÖFGREN, 2009) específicos. Ao serem questionados sobreas dinâmicas espaço-temporais relacionadas ao consumo, tais como a inserção da plataforma na rotina, os entrevistados enfatizaram o aspecto ritual. A Respondente 8 afirma: "Eu praticamente assisto Netflix demais. A Netflix é a minha rotina[...]". Os finais de semana, enquanto infraestruturas reconhecíveis de tempo (SHOVE; PANTZAR; WATSON, 2012), concentram um número maior de horas destinadas à prática, pois, na maioria dos casos, há maior disponibilidade de tempo em função da não realização de algumas atividades (como o trabalho):“Em final de semana [...] a gente assiste quatro, cinco, seis episódios de uma série, ou assiste dois, três filmes um atrás do outro" (Respondente 4).

Para a maioria dos entrevistados, em função da disponibilidade de tempo, as maratonas também ocorrem preferencialmente aos finais de semana, em sequências temporais que são originadas com a própria prática (SHOVE; PANTZAR; WATSON, 2012), embora para a maioria deles não haja um planejamento específico. Como explica a Respondente 7: "A série está boa e aí fico acordada até mais tarde. Mas geralmente não desmarco coisas ou decido que vou fazer só isso. Claro, às vezes acontece. Eu acordo cedo num sábado e aí coloco uma série e quando vejo são três horas da tarde". Ela conta que, por estar sozinha, perde noção do tempo.

Com relação aos espaços de prática, para além das affordances espaciais (MURRAY, 2012) - o espaço navegável da Netflix (telas de acesso e categorias de conteúdo da plataforma) -, os espaços físicos de utilização com maior ocorrência na pesquisa são o quarto e a sala. A partir da observação, pode-se depreender que não houve, de maneira geral, nenhuma modificação expressiva do espaço físico em função do consumo a televisão segue posicionada de maneira centralizada na sala de estar, mas agora com a companhia das telas do computador para a conexão via cabo HDMI ou dos telefones celulares e tablets com a conexão via Chromecast e Apple TV.

As relações familiares, para a maioria dos respondentes, também não sofreram alterações drásticas relacionadas à plataforma. Para a maior parte dos entrevistados, já não havia o costume de visualização familiar sincronizada no mesmo horário da televisão, como nos moldes tradicionais da reunião da família em frente à tela, em função das rotinas e gostos de cada um, e, portanto, com o streaming, essas relações se mantiveram. O relato da Respondente 9 também pode dar a dimensão das possibilidades em relação ao espaço, suporte e interação. Ela assiste pelo telefone celular, mas, ao mesmo tempo, usufrui do espaço em que a família está assistindo à televisão. "Eu assisto muito à Netflix na sala justamente por isso, eu não estou assistindo a mesma coisa que eles, mas eu estou na sala. Eles assistem algo na TV, e eu assisto outra coisa na Netflix" (Respondente 9). 
De toda forma, para além dos ritmos individualizados que seguem a configuração das atividades de cada entrevistado, é possível inferir algumas regularidades: a primeira delas é a convenção de estar em frente à tela depois das "obrigações" do dia - como um tipo de recompensa ou gratificação -; e a segunda é a autonomia no gerenciamento do tempo para o consumo, permitidos pelo sistema de streaming e suas respectivas possibilidades (BURROUGHS, 2015). Ou seja, ao funcionar como um repositório de conteúdos que estão disponíveis de acordo com a programação do usuário, a plataforma permite a autonomia de acesso no espaço e tempo disponíveis.

\section{A configuração das práticas e os fluxos de consumo na Netflix}

A partir das entrevistas, pode-se inferir que os vínculos relacionados ao consumo de conteúdo na Netflix conectam-se e organizam-se através da compreensão compartilhada (SCHATZKI, 1996). Ou seja, os entrevistados sabem os procedimentos necessários e no que consiste a plataforma; e, de maneira geral, seguem as regras e instruções, com relação ao acesso, estreia de conteúdos, e do conhecimento do repertório de limitações e potencialidades (CASTANHEIRA; POLIVANOV; MAIA, 2016). Além disso, percebem algumas affordances do sistema de maneira mais clara que outras. É preciso lembrar que essa é uma intencionalidade da própria empresa que, ao mesmo tempo que estimula a percepção de escolhas múltiplas, direciona o espectador em relação ao conteúdo que tenha a maior chance de engajamento (ARNOLD, 2016). Além, disso há o vínculo emocional e as dimensões afetivas que a plataforma adquire no cotidiano.

O uso da televisão é consenso dentre os entrevistados, mesmo para aqueles que utilizam outros artefatos rotineiramente. Essa preferência pode indicar a ligação com o habitus (BOURDIEU, 2009) incorporado, ou seja, a presença das experiências passadas, matrizes de percepções que são depositadas em cada organismo - o hábito adquirido ao longo da vida, de assistir televisão ao final de um dia de trabalho ou estudo ou tê-la ligada como companhia para outras atividades incluem-se nesse comportamento. Além disso, as referências ao tamanho da tela e à maior capacidade de concentração na televisão, somadas à necessidade de atender múltiplas telas ao mesmo tempo, guardam relações com o fenômeno de screeness, mais especificamente, a capacidade que as telas têm de produzir engajamento e atenção na relação entre indivíduos e objeto (INTRONA; ILHARCO, 2006; THRIFT, 2005).

No campo das dinâmicas relacionais, para os entrevistados, a interação com os amigos por meio de sites de redes sociais e aplicativos de mensagens enquanto consomem conteúdo acontece de maneira mais acentuada de forma assíncrona, ou seja, após o consumo de conteúdo, embora a interação durante a prática também seja realizada por grande parte dos usuários, que mantêm conversações por meio de outras telas quando o conteúdo não exige muita atenção, atividade para o qual desenvolveram competências. 
Essa interação ratifica a ideia de que, embora o consumo seja individualizado, o caráter social da plataforma se sobressai e, junto aos artefatos materiais, compõe as camadas deste consumo.

Nesse cenário, acessar e consumir o conteúdo disponibilizado na plataforma devido aos elementos que articula e à dimensão que assume na rotina dos seus usuários, estabelece-se como uma prática principal, capaz de ancorar, ao mesmo tempo, outras práticas relacionadas a ela (SWIDLER, 2001). A prática, como afirma Warde (2005), requer o consumo de determinados bens e serviços - neste caso, a aquisição da assinatura ou a obtenção da senha de alguém permite que o usuário tenha acesso à plataforma e usufrua das suas possibilidades- e, a partir disso, esse processo viabiliza outras práticas como a da socialização online ou presencial, a maratona, os spoilers ${ }^{10}$ - todas elas pressupondo um nível de entendimento, competências e engajamento.

Analisando as informações obtidas, é possível perceber que essas relações rotineiras entre as práticas e os usuários compreendem a criação de fluxos de consumo audiovisual no ambiente digital, que criam ritmos e sequências temporais de acordo com a sua necessidade, devido às possibilidades oferecidas pela plataforma. Esses momentos de consumo também acontecem de acordo com a variedade contextual, ou seja, é reduzido ou ampliado em função da sequência de atividades cotidianas, como por exemplo, o lançamento de uma nova série, períodos de folga ampliados, a necessidade de recompensas após um dia de trabalho árduo, entre outros.

A exemplo do conceito de fluxo da experiência da televisão tradicional (WILLIAMS, 2016), esses fluxos digitais (MCCORMICK, 2016) têm características próprias que podem ser observadas a partir do material coletado, tais como: a autonomia no sequenciamento temporal, a insaciabilidade, a influência do sistema de recomendação, o trânsito entre múltiplas telas e a interação síncrona ou assíncrona durante o consumo. Como nas verbalizações dos entrevistados, no caso da Netflix, esses fluxos já são naturalizados, e assistir à Netflix passa a integrar a rotina - um comportamento que, na maioria dos casos, embora não necessite de um planejamento específico, tem um caráter ritual.

As maratonas representam a autonomia presente nesse fluxo de consumo, embora elas existam há mais tempo que as plataformas de conteúdo sob demanda. A maioria dos entrevistados afirma assistir a uma sequência de episódios sem nenhum planejamento, em uma experiência imersiva que, como já foi mencionado, depende também do conteúdo exibido. Assim, ao mesmo tempo em que esse fluxo tem características de autonomia e sequenciamento do tempo, quando se trata do binge-watching, há que se considerar também o descontrole temporal relatado pelos entrevistados, o que, segundo Perks (2015), fortalece a imersão e intensidade da experiência da maratona. A prática também tensiona dois aspectos relacionados ao tempo e à mídia: a cotidianidade (SCANNELL,1996),

10 O termo vem de spoiling (ou, o ato de estragar a surpresa contando o final de uma narrativa). Segundo Jenkins (2009, p 59) a prática surgiu "do desencontro entre as temporalidades e geografias dos velhos e novos meios de comunicação". 
o fornecimento diário de um serviço em um fluxo contínuo e pelo qual os usuários tendem a esperar, e a serialidade (MOORES, 2005), a produção e exibição seriada (dia-a-dia, semana a semana) que trazem um senso de segurança. No primeiro caso, o da cotidianidade, o fornecimento é constante, ou seja, o conteúdo, via de regra, está disponível na Netflix (no caso de produções originais e outros conteúdos disponibilizados via binge-publishing ${ }^{11}$ ), e a espera se dá pelo momento do dia no qual haverá o acesso ou pela estreia de algum conteúdo específico. No caso da serialidade, a disponibilização total do conteúdo rompe esse aspecto - embora a produção e o formato sejam seriados, é o usuário quem define a sequência do consumo.

Por outro lado, pode-se atrelar o sentimento de vazio relatado pela maioria dos respondentes ao terminar uma maratona à ausência momentânea dessa segurança. A sensação de dever cumprido, mencionada por alguns entrevistados ao término da maratona, sinaliza a ligação com o desempenho de prática, além do consumo do conteúdo propriamente dito. Os fluxos digitais de consumo parecem indicar também uma relação de maior proximidade entre o usuário e as plataformas - e nesse sentido, para os entrevistados, em termos de afeição, a Netflix se mistura e, por vezes, equipara-se, ao afeto e engajamento com os conteúdos que transmite e/ou produz.

Outra característica associada a esse fluxo de consumo digital é a insaciabilidade com relação à disponibilização do conteúdo, o que aparece constantemente no discurso dos entrevistados e pode ser considerado um indicativo da mudança no status da audiência em relação aos meios de comunicação tradicionais em comparação ao consumo no ambiente digital - com a autonomia nos processos de consumo, parece ser cada vez mais difícil esperar pela nova temporada.

O sistema de recomendações personalizadas e os algoritmos tornam-se relevantes enquanto características do sistema e enquanto discurso ${ }^{12}$. A lógica de produção com base em dados coletados a partir dos hábitos de visualização agrada aos entrevistados, que demonstraram familiaridade com os mecanismos de ação da plataforma (conforme mencionado em tópico anterior, há o entendimento de que a empresa coleta os rastros de navegação e os utiliza). Assim, entende-se o sistema de recomendação como um aspecto ligado à dualidade da estrutura ${ }^{13}$, onde a agência humana e a estrutura se reproduzem e interagem constantemente (GIDDENS, 2009; JOHNSON, 1997): a Netflix (enquanto estrutura) proporciona aos seus usuários cada vez mais conteúdo, o que resulta em mais rastros de visualização - que ao mesmo tempo são utilizados para a manutenção do discurso da plataforma -, e de produção e aquisição de conteúdos, que são remodelados constantemente.

11 A disponibilização integral do conteúdo (todos os episódios de um seriado) ao mesmo tempo na plataforma.

12 Nesse sentido, o discurso refere-se a entrega de conteúdo personalizado enquanto estratégia da Netflix. De acordo com Burroughs (2015) existe a formação de uma audiência algorítmica, no sentido de que o público é impulsionado pelas afirmações discursivas das empresas de streaming de que os algoritmos estão entregando ao público o que estes já disseram ao algoritmo que desejam consumir.

13 "A estrutura como meio e o resultado da conduta que ela recursivamente organiza" (GIDDENS, 2009, p. 441). 
Neste cenário, portanto, ao menos dois fluxos puderam ser observados: a) o fluxo da produção de conteúdo, contínuo, que parte da própria Netflix, movimentado constantemente com a produção de originais, a inserção e remoção de obras do catálogo e o estímulo a criação de paratextos midiáticos ${ }^{14}$ e b) o fluxo do usuário, que é caracterizado pelo acesso rotineiro, fragmentado, autogerenciável e marcado pela insaciabilidade. Ambos os fluxos agem de forma recursiva, uma vez que, pelo observado nas entrevistas, o engajamento com o conteúdo determina a intensidade do consumo e a permanência na plataforma, bem como a atribuição de significados e o desempenho das práticas associadas. À variação de fluxos relacionam-se os aspectos materiais, importantes agentes condicionantes do processo, enquanto elementos que possibilitam a prática, o tempo, as dinâmicas espaço-temporais e relacionais que permeiam todo o processo.

A ideia de fluxo está relacionada a um movimento constante, cujos agentes humanos e não-humanos estão sempre se fazendo e desfazendo como redes (LEMOS, 2013) - essa também é uma característica das práticas, que não são uniformes e estão sempre em um processo de construção e reconstrução e dependem da sua reprodução para existirem. Esse movimento leva à percepção da rede sociotécnica formada pela Netflix, que mobiliza ao mesmo tempo as práticas e a estrutura, a partir da inserção na rotina dos usuários. A configuração das práticas relacionada à plataforma apresenta, portanto, uma relação recursiva com os elementos estruturais que estimulam o processo de consumo rotinizado, em um cenário no qual se destaca a interação entre a Netflix e o usuário e envolve interesses comerciais, elementos materiais, relações sociais, circulação e produção de conteúdo e as dimensões afetiva, cultural, política e econômica.

\begin{abstract}
Vanessa Amália Dalpizol Valiati é professora e pesquisadora do Mestrado em Indústria Criativa da Universidade Feevale (Novo Hamburgo, RS). É uma das líderes do C3DIG - Grupo de Pesquisa em Comunicação, Cultura e Consumo Digitais (FEEVALE) e do LIMC - Laboratório de Interação Mediada por Computador (UFRGS). É doutora em Comunicação e Informação pela Universidade Federal do Rio Grande do Sul (UFRGS) e mestre em Comunicação Social pela Pontifícia Universidade Católica do RS (PUCRS).

vanessavaliati@feevale.br
\end{abstract}

\title{
Referências
}

ARNOLD, S. Netflix and the Myth of choice/participation/autonomy. In: MCDONALD, K.; SMITHROWSEY, D. (Ed.). The Netflix effect: technology and entertainment in the 21 st Century. New York: BloomsburyAcademic, 2016. p. 69-85.

14 Gray (2010) explica que o termo cunhado por Gérard Genette (1987) representa tudo aquilo que acompanha um texto, como por exemplo, pôsters e cartazes de filme. 
BARBOSA, L. Sociedade de consumo. Rio de Janeiro: Jorge Zahar, 2004.

BOURDIEU, P. O senso prático. Petrópolis: Vozes, 2009.

BURROUGHS, B. Streaming media: audience and industry shifts in a networked society. PhD (Doctor of Philosophy) thesis, University of lowa, 2015. Disponível em: $\langle$ h3p://ir.uiowa.edu/etd/1833 $>$. Acesso em:10 dez. 2016.

CASTANHEIRA, J. C.; POLIVANOV, B.; MAIA, A. Does code dream of stuff? Dinâmicas materiais em mídias digitais. In: Encontro Anual dA Compós, 25, 2016, Goiania. Anais... Goiânia: Compós, 2016. p. 1 - 21. Disponível em: <http://www.compos.org.br/biblioteca/dinamicasmateriaisemmidiasdigitais_3274.pdf>. Acesso em: 15 nov. 2019.

CHRISTENSEN, T.; RØPKE, I. Can Practice Theory inspire studies of ICTs in everyday life? In: BRÄUCHLER, B.; POSTILL, J. (Org.). Theorising media and practice. Oxford e Nova York: Berghahn, 2010. p. $233-278$.

COULDRY, N. Theorising Media as a Practice. In: BRÄUCHLER, B.; POSTILL, J. (Org.). Theorising Media and Practice. Oxford e Nova York: Berghahn, 2010.

DOUGLAS, M; ISHERWOOD, B. O mundo dos bens: para uma antropologia do consumo. Rio de Janeiro: Editora UFRJ, 2013.

EHN, B.; LÖFGREN, O. Routines: Made and Unmade. In: SHOVE, E.; TRENTMAN, F.; WILK, R. Time, consuption and everyday life: practice, materiality and culture. Oxford and New York: BERG, 2009.

GIBSON, J. J. The Theory of affordances. In: SHAW, R. E; BRANSFORD, J (Eds.). Perceiving, acting, and knowing: toward an ecological psychology. Lawrence Erlbaum Associates: Hillsdale, 1977, p. 127-143.

GIDDENS, A. A constituição da sociedade. São Paulo: WMF Martins Fontes, 2009.

GRAY, J. Show sold separately: promos, spoilers, and other media paratexts. Nova York: NYU Press, 2010.

INTRONA, L.; ILHARCO. The meaning of screens: towards a phenomenological account of screenness. Human Studies, v. 29, p. 57-76, 2006. Disponível em: <http://www.ucp.pt/site/resources/documents/ FCH/F\%20llharco/c25659568qj27136\%20FINAL.pdf >. Acesso em: 14 mar. 2019.

JENKINS, H. Cultura da convergência. São Paulo: Aleph, 2009.

JENNER, M. Is this TVIV? On Netflix, TVIII and binge-watching. Sage. New Media \& Society, 2014, p. 1-17.

.Binge-watching: Video-on-demand, quality TV and mainstreaming fandom. Sage.International Journal of Cultural Studies, 2015, p.1-17.

JOHNSON, A. Dicionário de Sociologia: guia prático da linguagem sociológica. Rio de Janeiro: Zahar, 1997.

LEMOS, A. A comunicação das coisas: teoria ator-rede e cibercultura. São Paulo: Annablume, 2013.

MARTÍN-BARBERO. Dos meios as mediações: comunicação, cultura e hegemonia. Rio de Janeiro: Editora UFRJ, 2015.

MURRAY, J. Inventing the medium: principles of interaction design as a cultural practice. Cambrige: MIT Press, 2012.

MCCORMICK, C. "Forward is the battle cry": Binge-Viewing Netflix's House of Cards. In: MCDONALD, K.; SMITH-ROWSEY, D. (Ed.). The Netflix effect: technology and entertainment in the 21 st Century. New York: Bloomsbury Academic, 2016. 
MONTAÑO, S. Plataformas de vídeo: apontamentos para uma ecologia do audiovisual da web na contemporaneidade. Porto Alegre: Sulina, 2015.

MOORES, S. Media/Theory: thinking about media and communications. London and New York: Routledge, 2005.

PERKS, L. Media marathoning: immersions in morality. Nova York: Lexington Books, 2015.

POSTILL, J. Introduction: Theorising media and Practice. In: BRÄUCHLER, Birgit;

(Org.). Theorising Media and Practice. Oxford e Nova York: Berghahn, 2010.

RECKWITZ, A. Toward a Theory of Social Practices: A Development in Culturalist theorizing. European Journal of Social Theory, n. 5, 2002, p. 243-63.

SACCOMORI, C. Práticas de binge-watching na era digital: novas experiências de consumo de seriados em maratonas no Netflix. 246 f. Dissertação (Mestrado) - Faculdade de Comunicação Social, Programa de Pós-graduação em Comunicação Social, Pontifícia Universidade Católica do Rio Grande do Sul, Porto Alegre, 2016.

SCANNELL, P. Radio, television and modern life: a phenomenological approach. Oxford: Blackwell, 1996.

SCHATZKI, T. Introduction: practice theory. In: SCHATZCHI, T.; KNORR CETINA, K.; von SAVIGNY, E. (Orgs.). The practice turn in contemporary theory. London: Routledge, 2001.

Social practices: a Wittgensteinian approach to human activity and the social. Cambridge: Cambridge University Press, 1996.

SHOVE, E.; PANTZAR, M.; WATSON, M. The dinamics of social practice: theorizing. European Journal of Social Theory, n. 5, 2012, p. 243-63.

SWIDLER, A. What anchors cultural practices. In: SCHATZKI, T. R.; CETINA, K. K.; SAVIGNY, E. V. (Org.). The practice turn in contemporary theory. London and New York: Sage, 2001, p. 74-92.

THRIFT, N. Beyond Mediation: Three New Material Registers and Their Consequences. In: MILLER, Daniel. Materiality, 2013 Durham: Duke University Press, 2005.

VALIATI, V.A.D. "Você ainda está assistindo?": o consumo audiovisual sob demanda em plataformas digitais e a articulação das práticas relacionadas à Netflix na rotina dos usuários. 278 f. Tese (Doutorado), Programa de Pós-graduação em Comunicação e Informação, Universidade Federal do Rio Grande do Sul, 2018.

WARDE, A. Consumption and theories of practice. Journal of Consumer Culture. v. 5, n. 2, 2005, p. 131-153.

WILLIAMS, R. Televisão: tecnologia e forma cultural. São Paulo: Boitempo, 2016. 